\title{
Physical aging of glassy perfluoropolymers in thin film composite membranes. \\ Part II. Glass transition temperature and the free volume model
}

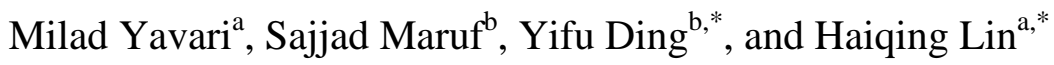 \\ ${ }^{a}$ Department of Chemical and Biological Engineering, University at Buffalo, \\ The State University of New York, Buffalo, NY 14260, U.S.A. \\ ${ }^{b}$ Department of Mechanical Engineering, University of Colorado at Boulder, \\ Boulder, CO 80309, U.S.A.
}

*Corresponding authors.

Haiqing Lin: Tel: +1-716-645-1856, fax: +1-716-645-3822; Email: haiqingl@buffalo.edu Yifu Ding: Tel: +1-303-492-2036, fax: +1-303-492-2574; Email: yifu.ding@colorado.edu

Revised submission to Journal of Membrane Science

$8 / 18 / 2016$ 


\section{ABSTRACT}

Thin film composite (TFC) membranes for gas separation often comprise a thin selective layer of a glassy polymer, which, however, suffers from physical aging, i.e., gas permeance decreases with time. This study aims to provide a mechanistic understanding of the effect of physical aging on permeance reduction in TFC membranes. The Part I study reports gas permeances in two-layer TFC membranes comprising perfluoropolymers of Teflon ${ }^{\circledR} \mathrm{AF}$ or Hyflon ${ }^{\circledR} \mathrm{AD}$ with thicknesses of $50-400 \mathrm{~nm}$. In this Part II study, apparent glass transition temperature $\left(T_{g}\right)$ of thin selective layers was determined in situ over time using a nano-thermal analysis (nano-TA). Physical aging decreases gas permeances and increases apparent $T_{g}$, and the rate of changes is more significant for thinner selective layers. For example, $\mathrm{N}_{2}$ permeance decreases from 1000 gpu to 550 gpu while apparent $T_{g}$ increases from $160{ }^{\circ} \mathrm{C}$ to $172{ }^{\circ} \mathrm{C}$ after aging for $2000 \mathrm{~h}$ in a membrane with 100-nm-thick Teflon AF1600. The measured $T_{g}$ values are used to derive polymer fractional free volume and physical aging rate. A simplified free volume model is used to successfully correlate the gas permeance reduction with $T_{g}$ increase during physical aging. Polymers with good stability of permeability should have low physical aging rate and high fractional free volume.

Keywords: Thin film composite membranes; Physical aging; Glass transition temperature; Free volume model; Perfluoropolymers 


\section{Nomenclature}

\begin{tabular}{|c|c|}
\hline$a$ & adjustable constant (cf. Eq. 6) \\
\hline$a_{1}$ & adjustable constant (cf. Eq. 5) \\
\hline$A_{A}$ & pre-exponential factor (Barrer, cf. Eq. 2) \\
\hline$b$ & adjustable constant (cf. Eq. 6) \\
\hline$b_{1}$ & adjustable constant (cf. Eq. 5) \\
\hline$B_{A}$ & a constant related to penetrant molecule size (cf. Eq. 2) \\
\hline$c$ & adjustable constant (cf. Eq. 6) \\
\hline$d$ & adjustable constant (cf. Eq. 6) \\
\hline$e$ & adjustable constant (cf. Eq. 6) \\
\hline$f$ & fractional free volume of a polymer \\
\hline$f_{0}$ & fractional free volume of a polymer at its $T_{g}$ \\
\hline$f_{48 h r}$ & fractional free volume of a polymer after aging for $48 \mathrm{~h}$ \\
\hline$f_{t}$ & fractional free volume of a polymer after an aging time of $t$ \\
\hline$l$ & thickness of a selective layer (nm) \\
\hline$P_{A}$ & permeability of gas A of a polymer (Barrer) \\
\hline$P_{A} / l$ & permeance of gas A in TFC membranes (gpu) \\
\hline$\left(P_{A} / l\right)_{48 h}$ & permeance of gas A after an aging time of $48 \mathrm{~h}$ (gpu) \\
\hline$\left(P_{A} / l\right)_{t}$ & permeance of gas A after an aging time of $t$ (gpu) \\
\hline$P_{t}$ & permeability of gas A of a polymer at an aging time of $t$ (Barrer) \\
\hline$t$ & time $(\mathrm{h})$ \\
\hline$T$ & temperature $\left({ }^{\circ} \mathrm{C}\right.$ or $\left.\mathrm{K}\right)$ \\
\hline TFC & thin film composite \\
\hline
\end{tabular}




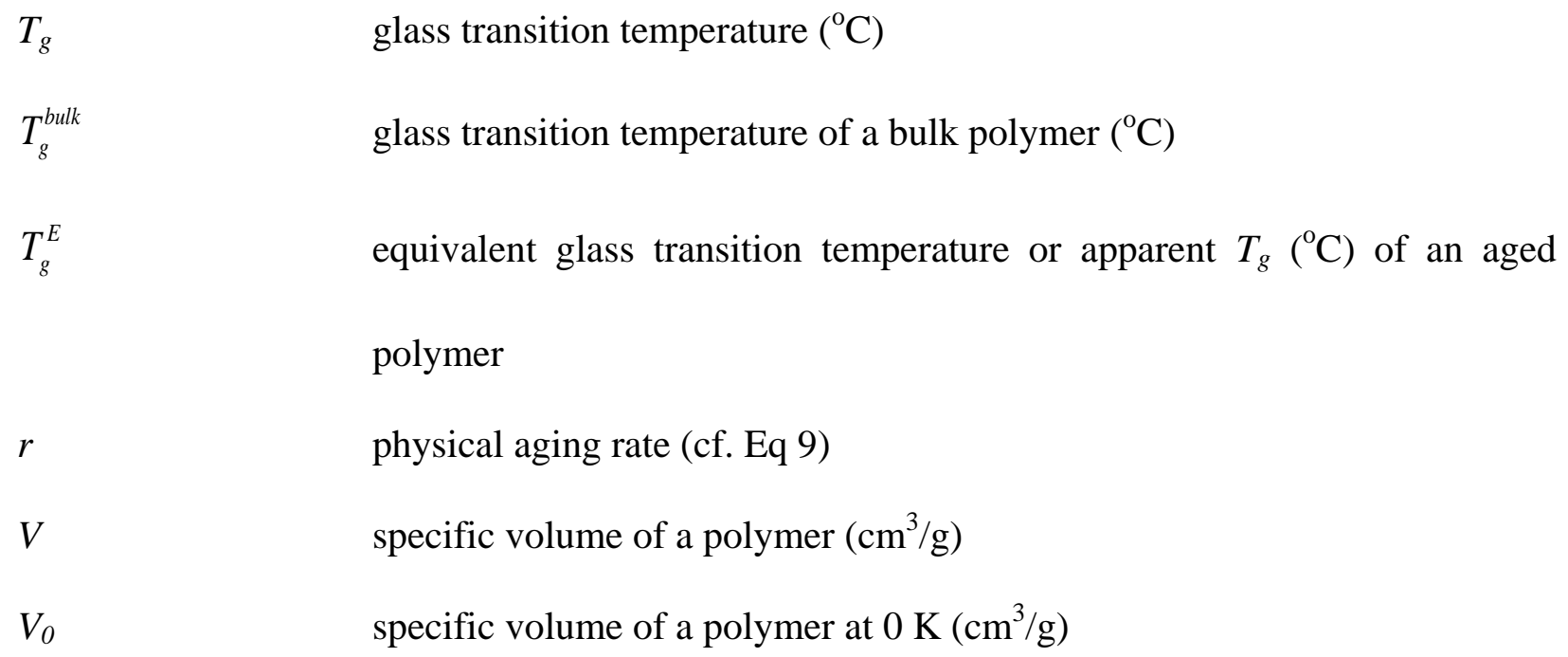

\section{Greek letters}

$\alpha_{g}$

$\beta_{1000 h}$

$\beta_{t}^{\prime}$

$\rho$

\section{Subscript}

$48 \mathrm{~h}$

$1000 \mathrm{~h}$

$t$

$r$

\section{Superscript}

bulk thermal expansion coefficient of a polymer at glassy state $\left(\mathrm{ppm} /{ }^{\circ} \mathrm{C}\right)$

ratio of gas permeability at an aging time of $1000 \mathrm{~h}$ to that at $1 \mathrm{~h}$

relative permeability at an aging time of $t$ to that at $48 \mathrm{~h}$ (cf. Eq. 7)

polymer density $\left(\mathrm{g} / \mathrm{cm}^{3}\right)$ measurement at an aging time of $48 \mathrm{~h}$

measurement at an aging time of $1000 \mathrm{~h}$

measurement at an aging time of $t(\mathrm{~h})$

relative property

property of a bulk polymer 


\section{Introduction and Background}

Glassy polymers have been widely explored for membrane gas separation, due to their rigid structure and strong size sieving ability [1,2]. However, when these polymers are made into thin film composite (TFC) membranes, their gas permeability often decreases with time due to physical aging, which limits their potential for industrial applications [3-6]. For example, Part I of this study investigates TFC membranes with selective layers of glassy perfluoropolymers such as Teflon ${ }^{\circledR}$ AF1600 and Hyflon ${ }^{\circledR}$ AD and demonstrates that gas permeance decreases with time, and the decrease is more significant for membranes with thinner selective layers $[7,8]$. The reduction rate of gas permeability in polymers may be decreased by blending with nanoparticles [9-11]. However, there lacks a understanding of the relationship of polymer structure and gas permeability reduction, especially for thin films in TFC membranes.

Glassy polymers are at non-equilibrium state, and polymer chains relax toward lower energy states over time (i.e., aging), decreasing polymer specific volume (V) [12-14]. As shown in Fig. 1, the decrease in $V$ decreases polymer fractional free volume $(f)$, a key parameter determining gas diffusivity and thus permeability in polymers $[4,15]$. The $f$ value is usually estimated as follows:

$f=\frac{V-V_{o}}{V}$

where $V_{o}$ is the specific occupied volume at $0 \mathrm{~K}$ and it is estimated as 1.3 times the van der Waals volume [16]. The van der Waals volume is usually estimated using Bondi's group contribution method [16].

The permeability of gas component $\mathrm{A}\left(P_{A}\right.$ in Barrer) in nonporous polymers can be related to the $f$ by [17-20]: 
$P_{A}=A_{A} \exp \left(-\frac{B_{A}}{f}\right)$

where $A_{A}$ is a pre-exponential factor (Barrer) and $B_{A}$ is a constant increasing with increasing penetrant molecule size.

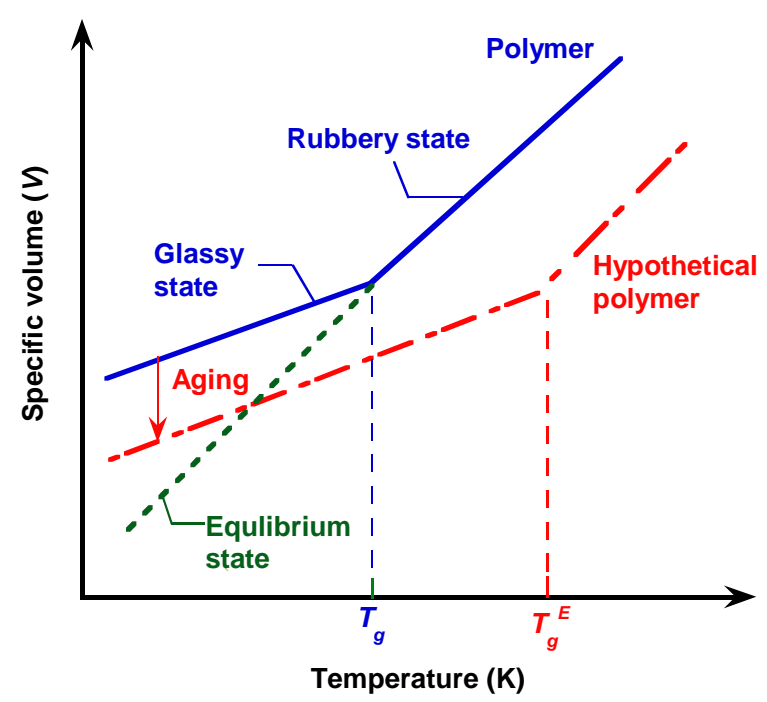

Fig. 1. Schematic of polymer specific volume $(V)$ as a function of temperature. The polymer has a glass transition temperature of $T_{g}$. Physical aging decreases $V$, and the aged polymer has an equivalent glass transition temperature of $T_{g}^{E}$ (or apparent $T_{g}$ ).

The aged polymer has lower free volume or more compact structure than the unaged one. To reflect the difference, a concept of equivalent glass transition temperature $\left(T_{g}^{E}\right)$ is defined in Fig.

1. A hypothetical polymer with a glass transition temperature of $T_{g}^{E}$ is assumed to have the same thermal expansion coefficients as the unaged polymer, and the same specific volume as the aged polymer at the temperature of interest. Therefore, the aged polymer is considered to have a glass transition temperature of $T_{g}^{E}$ (or apparent $T_{g}$ ), which is higher than the original $T_{g}$ to differentiate the aged polymer from the unaged one. Consequently, the $f$ value for the aged glassy polymer can be related with the apparent $T_{g}$ using the following equation [19-22]: 
$f=f_{0}+\alpha_{g}\left(T-T_{g}\right)$

where $f_{0}$ is a constant indicating the free volume at $T_{g}$, and $\alpha_{g}$ is thermal expansion coefficient of the polymer at glassy state. The values of $f_{0}$ and $\alpha_{g}$ are regarded as constants during the aging process [23]. Eq. 3 can be used to estimate the $f$ values for polymer thin films at various thicknesses and aging times, since both film thickness and aging time influence the $T_{g}$ values.

Combining Eqs. 2 and 3 gives the following expression:

$P_{A}=A_{A} \exp \left[-\frac{B_{A}}{f_{0}+\alpha_{g}\left(T-T_{g}\right)}\right]$

Eq. 4 gives a correlation between gas permeability at a given $T$ and apparent $T_{g}$. As shown in Fig. 1, physical aging increases the apparent $T_{g}$, and thus decreases $f$ and gas permeability.

To examine the relationship of $f$ and gas permeability for TFC membranes during physical aging, reliable measurements of the $T_{g}$ of the selective layer in situ are required. Though several techniques are available to measure $T_{g}$ of thin polymer films, such as differential scanning nano-calorimetry [24] and ellipsometry [25,26], they cannot be used to monitor the $T_{g}$ of the selective layer in the TFC membranes in situ due to the interference of the microporous support beneath the selective layer. Moreover, both experimental and simulation work have shown that the $T_{g}$ of thin film glassy polymers depends on the processing history and substrates. For example, $T_{g}$ of the thin films could be higher or lower than that of bulk polymers, depending on the interactions between the polymer and substrate [26-30], which again calls for techniques that can probe the $T_{g}$ of the membrane selective layer in situ.

Recently, a new AFM-based technique, nano-thermal analysis (nano-TA), has been used to measure the softening temperature of thin films in situ [31,32]. Briefly, a resistive heater 
embedded in the cantilever controllably heats the AFM probe with a tip radius less than $30 \mathrm{~nm}$. When the film surface in contact with the tip is heated, the local thermal expansion of the polymer will induce the upward deflections of the cantilever. Once the temperature rises above the "softening temperature" of the polymer surface, the tip would sink into the film, causing downward deflection. This onset of change in tip deflection direction provides a good estimate

of the "softening temperature" (or apparent $T_{g}$ or $T_{g}^{E}$ ) for the thin film in the nanoscale. This non-intrusive technique is ideal to monitor thin film properties in composite structures in situ as a function of aging time.

In this Part II of the study, the apparent $T_{g}$ of the thin selective layers with various thicknesses and aging time in the TFC membranes was determined, and the results are correlated with the polymer $f$ and thus gas permeance using a simplified free volume model. This work, for the first time, directly determined the $T_{g}$ of the selective layer in TFC membranes during physical aging, and provides a quantitative interpretation of the relationship between physical aging and gas permeability reduction.

\section{Experimental}

\subsection{Materials and preparation of TFC membranes}

The materials and the preparation of TFC membranes were described in detail in the Part I of this study [7]. Briefly, TFC membranes were prepared by coating of perfluoropolymer solutions on top of polyethersulfone (PES) porous supports (PES-2 from Ultura ${ }^{\mathrm{TM}}$ High Recovery Membrane Technology, Long Beach, CA) using an automatic draw machine (DP-8301, The Paul N. Gardner Company, Pompano Beach, FL). Pure-gas permeance in the TFC membranes was determined using a constant pressure/variable volume apparatus at $35{ }^{\circ} \mathrm{C}$ [33]. 


\subsection{Preparation of freestanding perfluoropolymer films}

To prepare freestanding films, homogeneous solutions containing 15 wt.\% perfluoropolymers in Novec 7200 were first casted on a glass plate using a casting knife (The Paul N. Gardner Co., Pompano Beach, FL). Subsequently, the films were dried in the air for 18 $\mathrm{h}$ and then immersed in distilled water to detach from the glass plate. Finally, the films were dried in a vacuum oven at $80{ }^{\circ} \mathrm{C}$ for $24 \mathrm{~h}$ to remove the water and residual solvent. The films typically have a thickness of $10-20 \mu \mathrm{m}$. Pure-gas permeability of the obtained films was determined using a constant volume/variable pressure apparatus at $35^{\circ} \mathrm{C}$ [33].

\subsection{Determination of $T_{g}$ in bulk polymers using differential scanning calorimetry (DSC)}

The $T_{g}$ of bulk perfluoropolymers was determined using differential scanning calorimetry (DSC) (DSC 204 F1, Netzsch-Geratebau GmbH, Selb, Germany). The samples were heated from $25{ }^{\circ} \mathrm{C}$ to $200{ }^{\circ} \mathrm{C}$ at a ramping rate of $10{ }^{\circ} \mathrm{C} / \mathrm{min}$ under nitrogen purge. The $T_{g}$ value is defined as the midpoint of the glass transition region during the first heating cycle.

\subsection{Determination of apparent $T_{g}$ of the selective layer in TFC membranes using nano-TA}

Nano-TA (Anasys Instrument Inc., Santa Barbara, CA) measurements were performed using a custom-made thermal lever probe (AN2-300) with a heating rate of $2{ }^{\circ} \mathrm{C} / \mathrm{s}$ and temperature ranging from $25{ }^{\circ} \mathrm{C}$ to $225^{\circ} \mathrm{C}$. Prior to the measurements, the temperature-voltage relationship was calibrated with three semicrystalline polymer standards with known values of melting temperature, polycaprolactone (with a melting temperature of $55{ }^{\circ} \mathrm{C}$ ), polyethylene $\left(116{ }^{\circ} \mathrm{C}\right)$ and polyethylene terephthalate $\left(235{ }^{\circ} \mathrm{C}\right)$. For each sample, six measurements at different locations 
across the surface of the TFC membranes were performed, and the average values of the $T_{g}$ are reported here.

\section{Results and Discussion}

\section{1. $T_{g}$ of perfluoropolymers determined using nano-TA}

Fig. 2 shows exampled deflection curves of nano-TA for Teflon AF1600 in TFC membranes after being aged for about $744 \mathrm{~h}$. The deflection approaches a maximum at the apparent $T_{g}$ of the thin film polymer. More specifically, Fig. 2a shows the deflection curves at five different positions of a 50-nm-thick Teflon AF1600, which demonstrate the reproducibility of nano-TA. Fig. 2b shows deflection curves of Teflon AF1600 with different film thicknesses in TFC membranes after aging for $744 \mathrm{~h}$. The deflection changing rate is related to the thermal expansion (in the vertical direction) of the membrane (including the selective layer and porous substrate) in contact with the thermal probe. Because of the interplay between heat transfer and contact mechanics between the tip of the probe and the membrane, there is often no direct correlation between the selective layer thickness and deflection changing rate. Nevertheless, this difference does not affect the determination of $T_{g}$ of the selective layer using the change of deflection, which is exclusively caused by the softening of the selective layer. The apparent $T_{g}$ values depend on the thickness of the selective layers. For example, the selective layer with a thickness of $50 \mathrm{~nm}, 100 \mathrm{~nm}, 175 \mathrm{~nm}$ and $370 \mathrm{~nm}$ exhibits an apparent $T_{g}$ value of $170.8{ }^{\circ} \mathrm{C}$, $168.9{ }^{\circ} \mathrm{C}, 163.1{ }^{\circ} \mathrm{C}$ and $164.1{ }^{\circ} \mathrm{C}$, respectively. The standard deviation of the measured apparent $T_{g}$ values is within $1{ }^{\circ} \mathrm{C}$. The detailed discussion on the effect of film thickness and aging time on the apparent $T_{g}$ is provided in Section 3.3. 
(a)

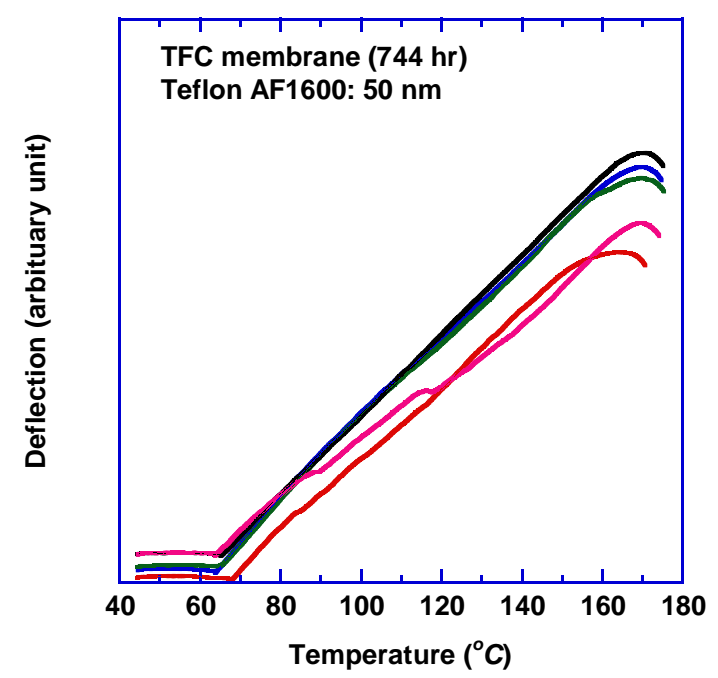

(b)

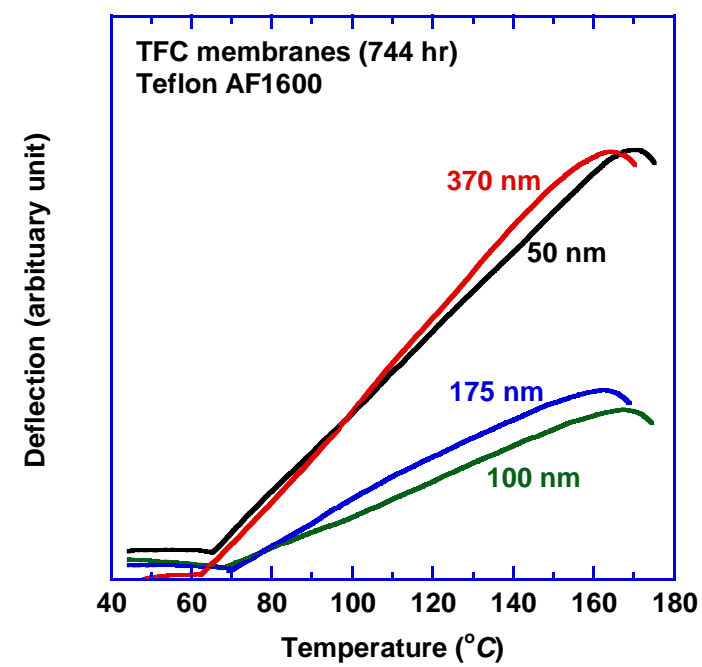

Fig. 2. Exampled deflection curves from nano-TA. (a) A 50-nm-thick selective layer in a TFC membrane, and (b) selective layers with varying thicknesses in TFC membranes. All membranes comprise selective layers of Teflon AF1600 after aging for about $744 \mathrm{~h}$.

The polymer $T_{g}$ is often determined using DSC, while the nano-TA provides the information of the polymer softening temperature or apparent $T_{g}[31,32]$. Table 1 compares the $T_{g}$ values obtained from DSC and nano-TA for the relevant perfluoropolymers in freestanding films of 10 $20 \mu \mathrm{m}$ thickness. There is excellent consistency in $T_{g}$ values obtained from both methods validating the use of nano-TA for determining the $T_{g}$ for thin film polymers in TFC membranes. 


\section{Table 1}

Chemical structure, thermal expansion coefficient $\left(\alpha_{g}\right)$ and $f$ values of perfluoropolymers, as well as $T_{g}$ values of polymer films of $10-20 \mu \mathrm{m}$ measured by nano-TA and DSC.

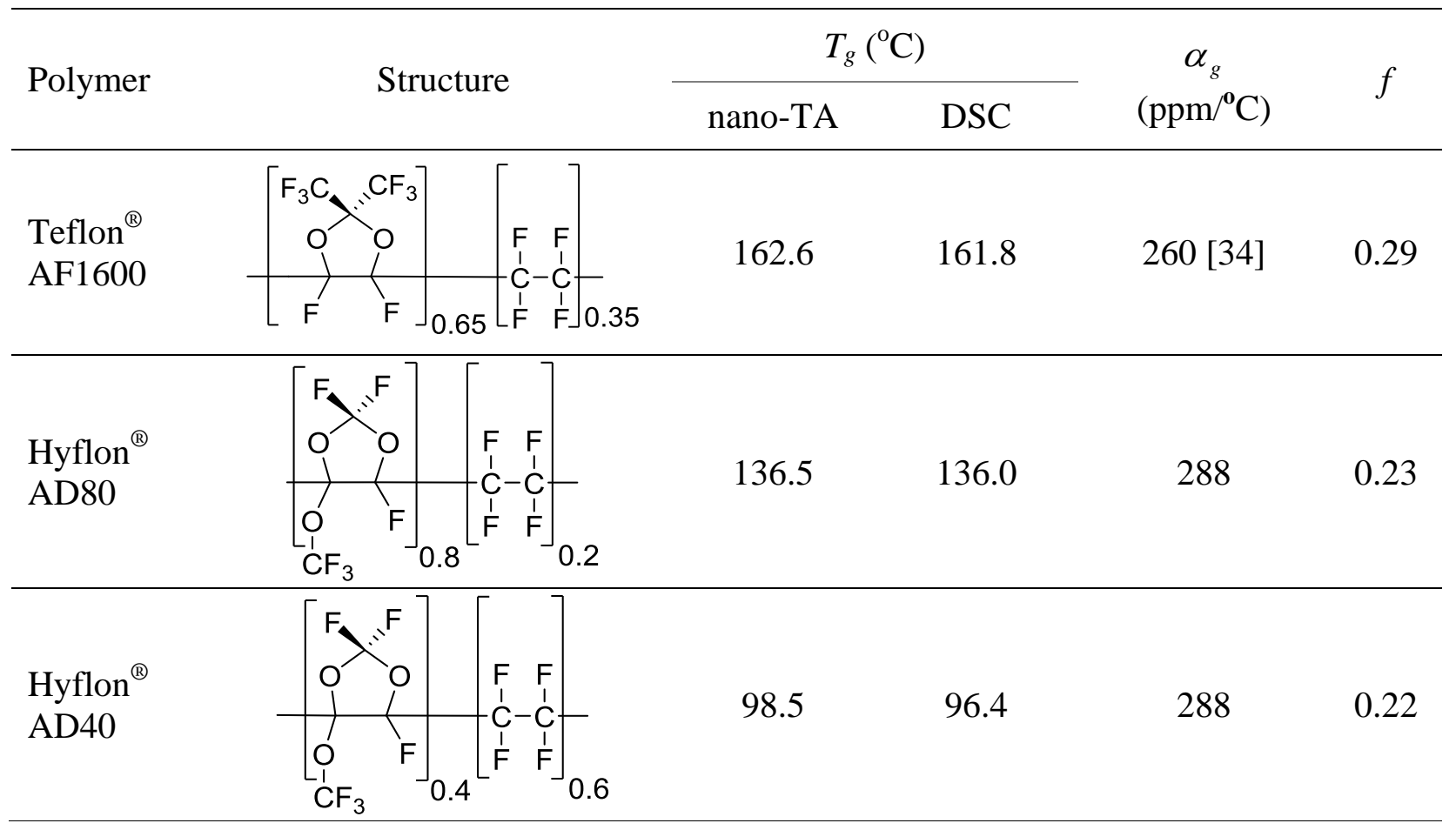

To further validate the technique, nano-TA was used to determine the $T_{g}$ of the thin selective layer film in the TFC membrane and the same film isolated on top of a silicon wafer after removing the microporous support. First, the $T_{g}$ of the selective layer in TFC membranes was determined. Second, the TFC membrane was immersed in dimethylformamide (DMF) to dissolve the PES support [7], and the thin perfluoropolymer film was collected on top of the wafer. Third, after drying in a vacuum oven at $80{ }^{\circ} \mathrm{C}$ for 2 hours, the isolated film was measured again using nano-TA. The results are summarized in Table 2 for membranes comprising Teflon AF1600 and Hyflon AD80. Both measurements agree reasonably well, confirming the reliability of the nano-TA technique in determining $T_{g}$ values for thin films in situ. The slightly lower $T_{g}$ values for the thin films on the wafer than that in the TFC membranes may be caused by the exposure to DMF or the difference in the substrates [35]. 


\section{Table 2}

$T_{g}$ comparison of perfluoropolymer thin films in TFC membranes with that on top of a silicon wafer after removing the porous support. Both measurements were performed using nano-TA. The TFC membranes were aged for $720 \mathrm{~h}$ before the $T_{g}$ measurement.

\begin{tabular}{lccc}
\hline \multirow{2}{*}{ Polymer } & $\begin{array}{c}\text { Thickness } \\
(\mathrm{nm})\end{array}$ & \multicolumn{2}{c}{$T_{g}$ of thin films $\left({ }^{\circ} \mathrm{C}\right)$} \\
\cline { 3 - 4 } & 370 & 164.2 & on a wafer \\
\hline Teflon AF1600 & 350 & 134.4 & 162.0 \\
\hline Hyflon AD80 & & & 133.0 \\
\hline
\end{tabular}

\subsection{Effect of the selective layer thickness on its $T_{g}$ in TFC membranes}

Fig. 3 shows the effect of the selective layer thickness on its $T_{g}$ in perfluoropolymers-based TFC membranes after aging for $48 \mathrm{~h} . T_{g}$ decreases with decreasing film thickness, which agrees well with the observation for thin film polymers with free surface [36,37]. The surface layer exposed to air is believed to be much more mobile than the bulk polymer and therefore, it exhibits lower $T_{g}$ than the bulk ( $T_{g}^{b u l k}$ ). As the film becomes thinner, the surface layer becomes more dominant and therefore, the overall film shows a decreased $T_{g}$ with decreasing thickness $[36,38]$. The following empirical equation has been used to describe the effect of film thickness on $T_{g}$ values [29,38,39]:

$T_{g}=T_{g}^{b u l k}\left(a_{1} l+b_{1}\right)$

where $a_{1}$ and $b_{1}$ are adjustable constants, and $l(\mathrm{~nm})$ is the film thickness. The best fits using Eq. 5 are shown in Fig. 3a, demonstrating that the Eq. 5 can satisfactorily describe the data. 
(a)

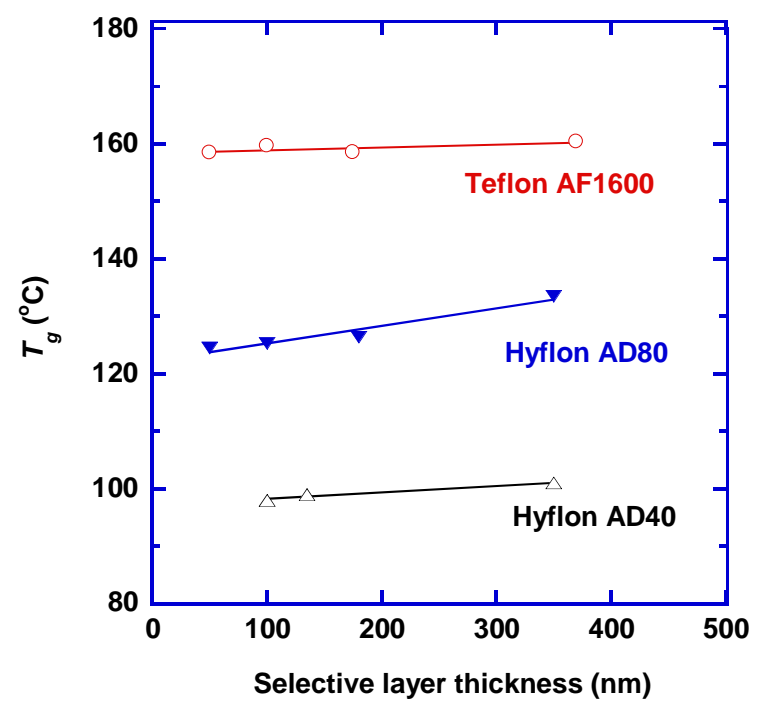

(b)

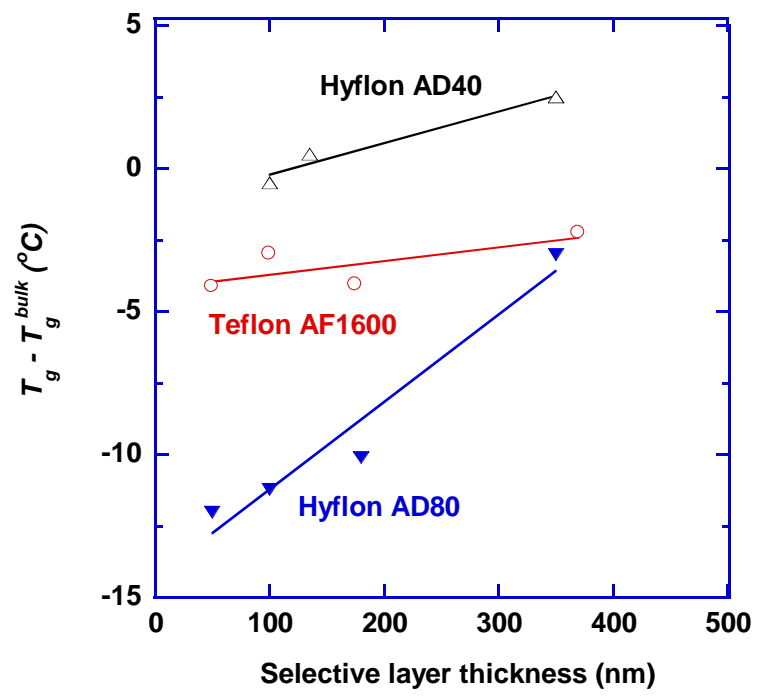

Fig. 3. Effect of the selective layer thickness in TFC membranes on (a) the apparent $T_{g}$ and (b) deviation of $T_{g}$ from the bulk polymer $T_{g}^{b u l k}$ for Teflon AF1600 (०), Hyflon AD80 ( $\left.\nabla\right)$ and Hyflon AD40 $(\Delta)$ after aging for $48 \mathrm{~h}$. The linear lines are the best fits based on Eq. 5 .

Fig. $3 \mathrm{~b}$ directly presents the deviation of $T_{g}$ from the bulk polymer $T_{g}^{\text {bulk }}$ for TFC membranes. The thin films of Teflon AF1600 and Hyflon AD80 exhibit $T_{g}$ values lower than the bulk. However, Hyflon AD40 shows an opposite trend, i.e., thin films exhibit higher $T_{g}$ values than the bulk. This behavior can be ascribed to physical aging and will be discussed in detail in Section 3.3. All films show the apparent $T_{g}$ increasing with physical aging.

\subsection{Effect of physical aging on the apparent $T_{g}$ of perfluoropolymers in TFC membranes}

Fig. 4 presents the apparent $T_{g}$ values of perfluoropolymer thin films in TFC membranes as a function of film thickness and aging time, which were determined using nano-TA. In general, the $T_{g}$ values increase with aging time and increasing film thickness. As an example (cf. Fig. 4a), Teflon AF1600 initially shows lower $T_{g}$ values for thinner films at an aging time of $48 \mathrm{~h}$. However, after aging for $3600 \mathrm{~h}$, thinner films such as $l=50 \mathrm{~nm}$ show higher $T_{g}$ than thicker 
films such as $l=370 \mathrm{~nm}$. This is presumably due to the more rapid aging rate in the thinner films, leading to more compact structure and thus higher apparent $T_{g}$ values. For the TFC membranes based on Hyflon AD, the long-term $T_{g}$ values for thinner films also approach that of thicker films, though thick films always exhibit higher $T_{g}$ values than the thinner ones.

The effect of film thickness and aging time on the $T_{g}$ values can be described using the following empirical equation:

$$
\frac{T_{g}}{T_{g}^{b u l k}}=(a \ln t+b) l+c(\ln t)^{2}+d
$$

where $a, b, c$ and $d$ are adjustable constants. Eq. 6 can be reduced to Eq. 5 at a fixed aging time. The best fits based on Eq. 6 are presented in Fig. 4, with the values of the adjustable parameters shown in Table S1 in the Supplemental Information. There is a reasonably good agreement between the experimental and modeling data.

This empirical Eq. 6 can be used to interpret the separated effect of film thickness and aging time on the $T_{g}$ of the thin films, which further confirms that thinner films may have lower $T_{g}$ than thicker ones at earlier stage of aging, and then higher $T_{g}$ after long-term aging. Combining Eqs. 6 and 3 also allows the evaluation of effect of film thickness and aging time on the $f$ values. 
(a)

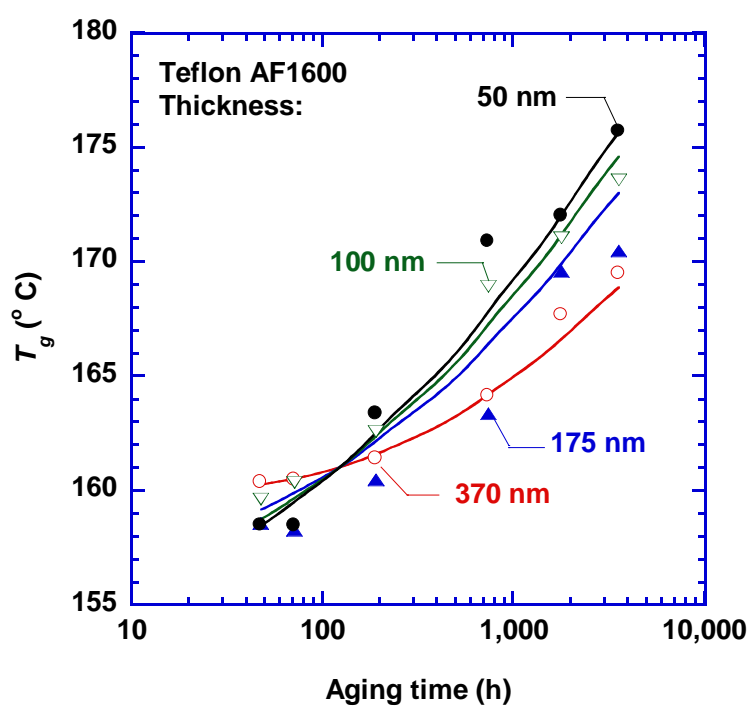

(b)

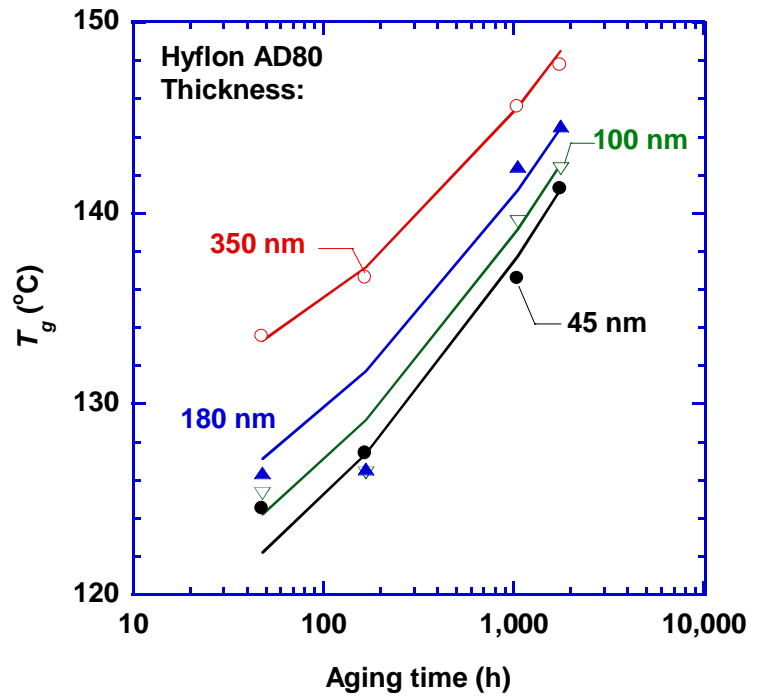

(c)

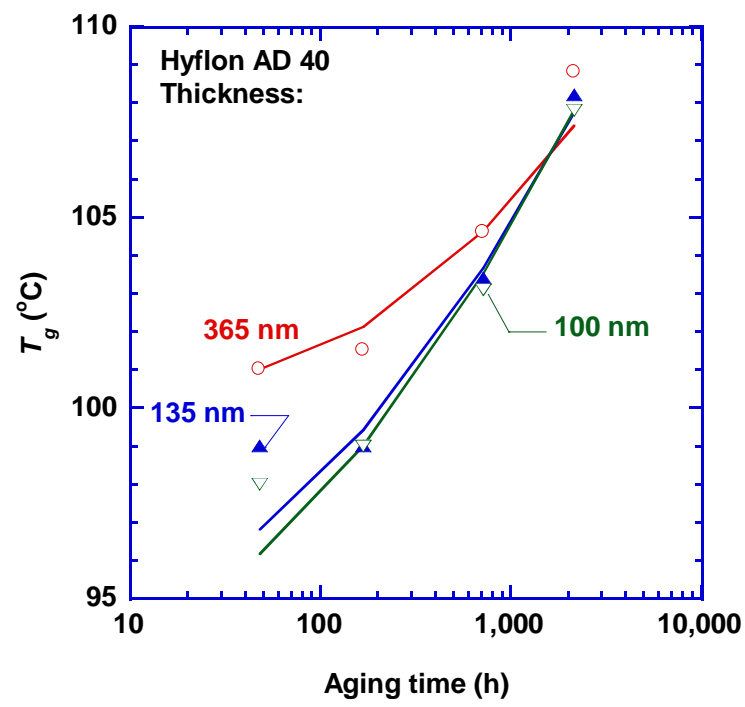

Fig. 4. $T_{g}$ of the selective layers of (a) Teflon AF1600, (b) Hyflon AD80, and (c) Hyflon AD40 with varying thicknesses in TFC membranes as a function of aging time. The symbols represent the measured $T_{g}$ and the lines are the best fits based on Eq. 6 with the values of adjustable parameters recorded in Table S1 in the Supplemental Information.

\subsection{Relationship between the $T_{g}$ increase and permeance reduction during aging}

Fig. 5 exhibits the relative $\mathrm{N}_{2}$ permeance $\left(\beta_{t}{ }^{\prime}\right)$ and the $T_{g}$ of the selective layer in a TFC membrane comprising 100-nm-thick Teflon AF1600. The $\beta_{t}{ }^{\prime}$ is defined using the following expression [40-42]: 
$\ln \beta_{t}{ }^{\prime}=\ln \left(\frac{P_{t}}{P_{48 h}}\right)=\ln \left(\frac{\left(P_{A} / l\right)_{t}}{\left(P_{A} / l\right)_{48 h}}\right)=B_{A}\left(\frac{1}{f_{48 h}}-\frac{1}{f_{t}}\right)$

where $\left(P_{A} / l\right)_{t}$ and $\left(P_{A} / l\right)_{48 h}$ are the gas permeance determined at the aging time of $t$ and $48 \mathrm{~h}$, respectively. The gas permeance at $48 \mathrm{~h}$ is used as reference since the first $T_{g}$ measurement for the TFC membranes was made at $48 \mathrm{~h}$. As shown in Fig. 5, the $\beta_{t}{ }^{\prime}$ value decreases with aging time, as described in the Part I study [7], while the apparent $T_{g}$ increases with aging time.

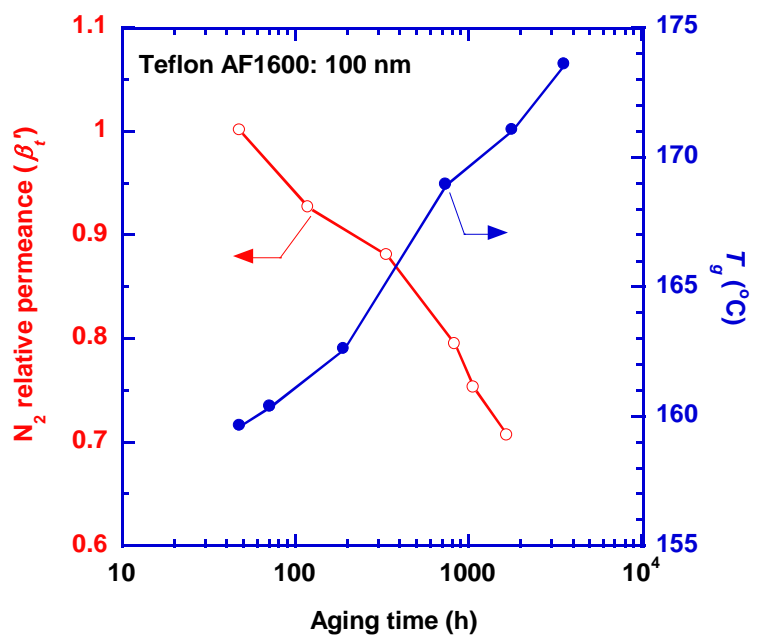

Fig. 5. Effect of physical aging on the relative $\mathrm{N}_{2}$ permeance $\left(\beta_{t}{ }^{\prime}\right)$ at $35{ }^{\circ} \mathrm{C}$ and $T_{g}$ values of a 100-nm-thick Teflon AF1600 in a TFC membrane.

To understand the relationship between the permeance reduction and $T_{g}$ increase during the physical aging, the following equation is derived by combining Eqs. 1 and 7:

$$
-\ln \beta_{t}{ }^{\prime}=\frac{\alpha_{g} B_{A}\left(T_{g, t}-T_{g, 48 h}\right)}{f_{t} \cdot f_{48 h}}=\frac{\alpha_{g} B_{A}\left(T_{g, t}-T_{g, 48 h}\right)}{f_{48 h}^{2}}
$$

Eq. 8 assumes that $f_{48 h} f_{t}$ equals to $f_{48 h}^{2}$ to simplify the analysis. To validate this assumption, Eq. 3 is used to estimate the difference between $f_{48 h}$ and $f_{t}$ for 50-nm-thick Teflon AF1600 in a TFC membrane, which yields a value of 0.005. Such difference is negligible compared with the 
$f$ value (0.29) of Teflon AF1600, as shown in Table 1.

Fig. 6 shows the correlation between the $\beta_{t}{ }^{\prime}$ values for $\mathrm{N}_{2}$ and $\mathrm{CH}_{4}$ and the $T_{g, t}$ values for the selective layers in TFC membranes. The $\beta_{t}{ }^{\prime}$ values of $\mathrm{CO}_{2}$ and $\mathrm{H}_{2}$ show similar trend and they are presented in the Supplemental Information. Since the gas permeance and $T_{g, t}$ were often determined at different times, the $\beta_{t}{ }^{\prime}$ values are taken from experiments, while the $T_{g, t}$ values are calculated using Eq. 6 for the times when the gas permeances were determined. All the data can be reasonably modeled by Eq. 8 , confirming that both $T_{g}$ increase and permeance decrease can be ascribed to physical aging of thin films.

(a)

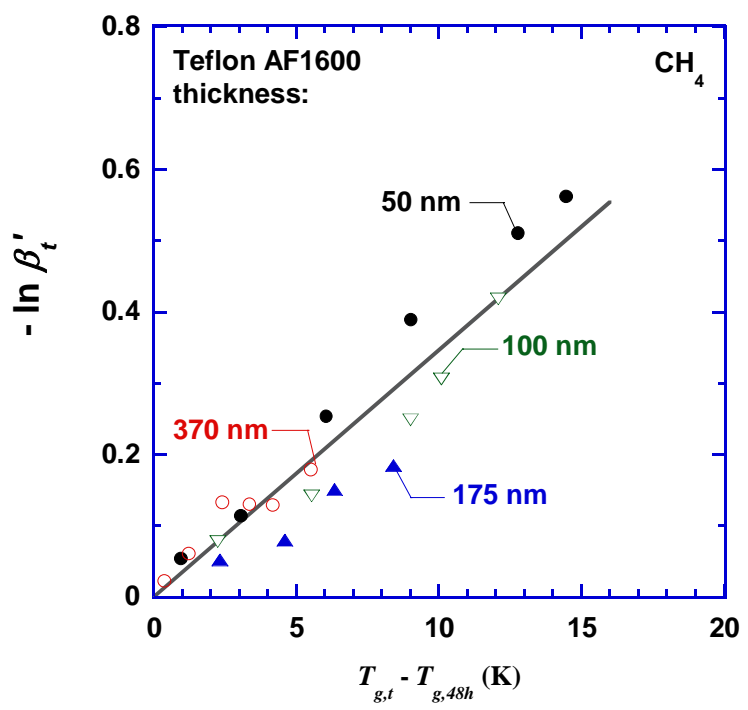

(b)

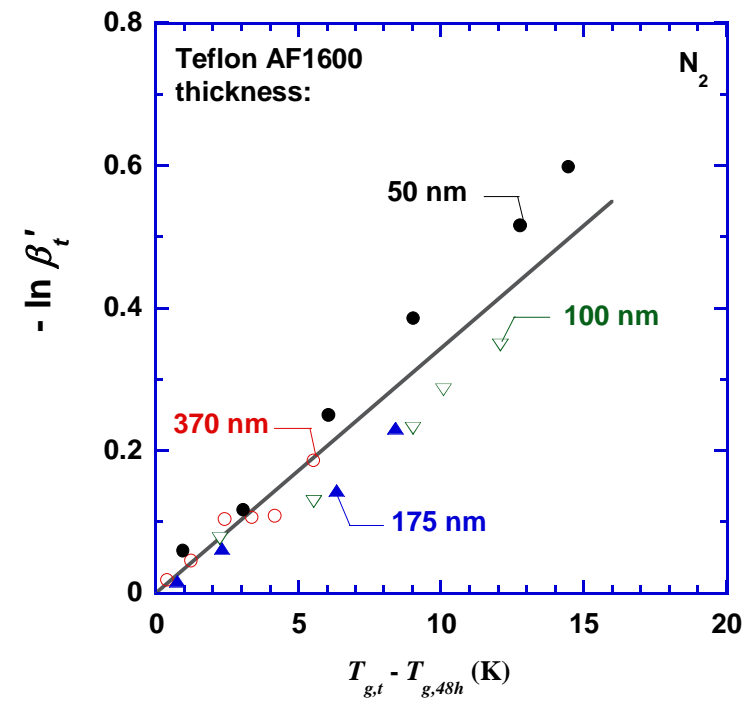


(c)

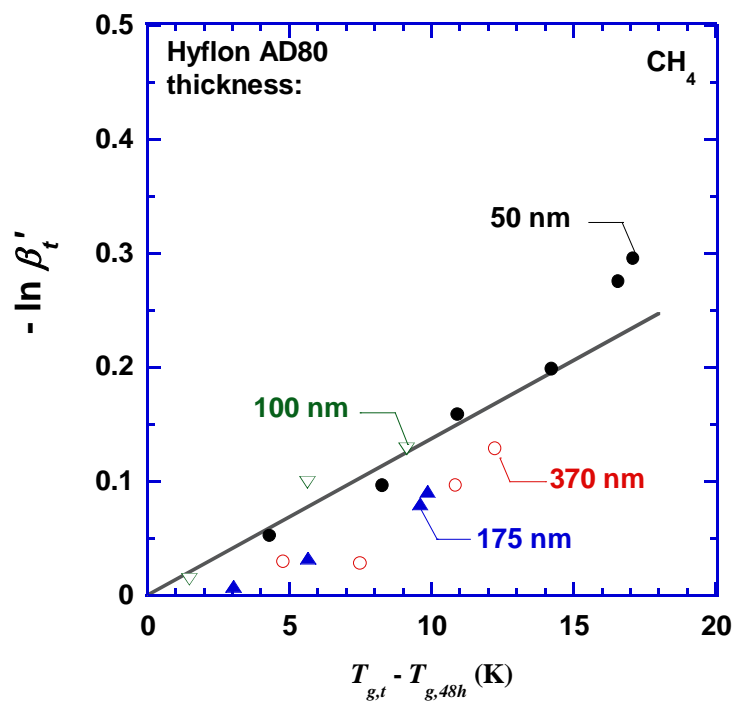

(e)

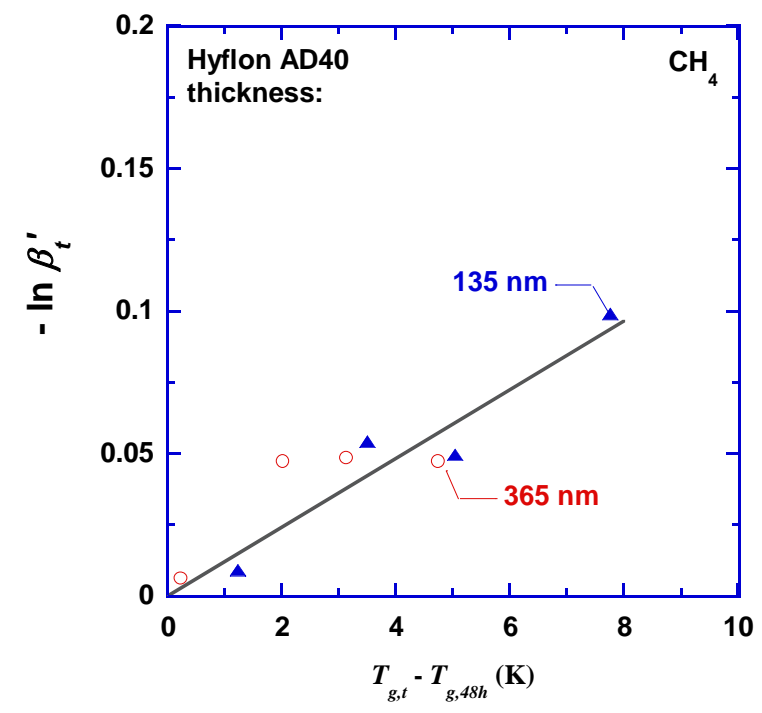

(d)

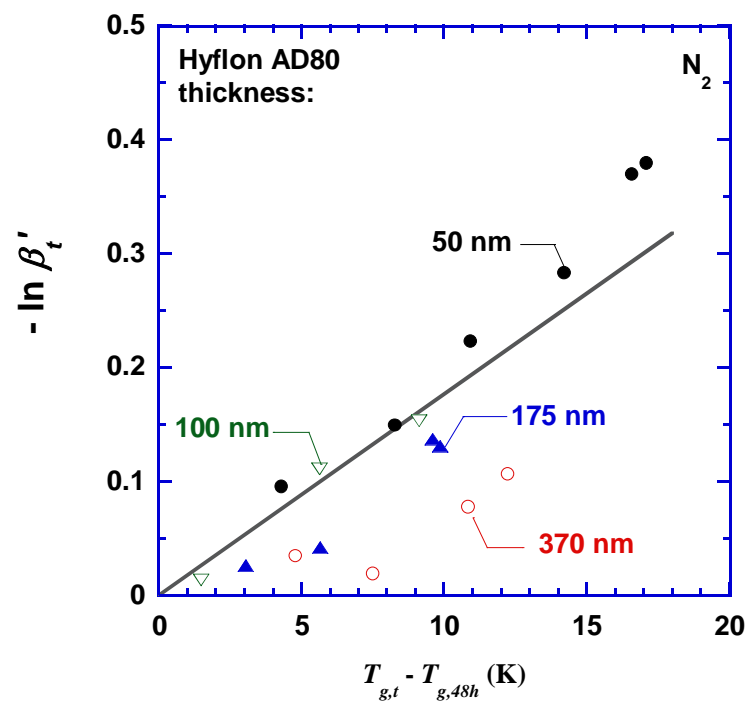

(f)

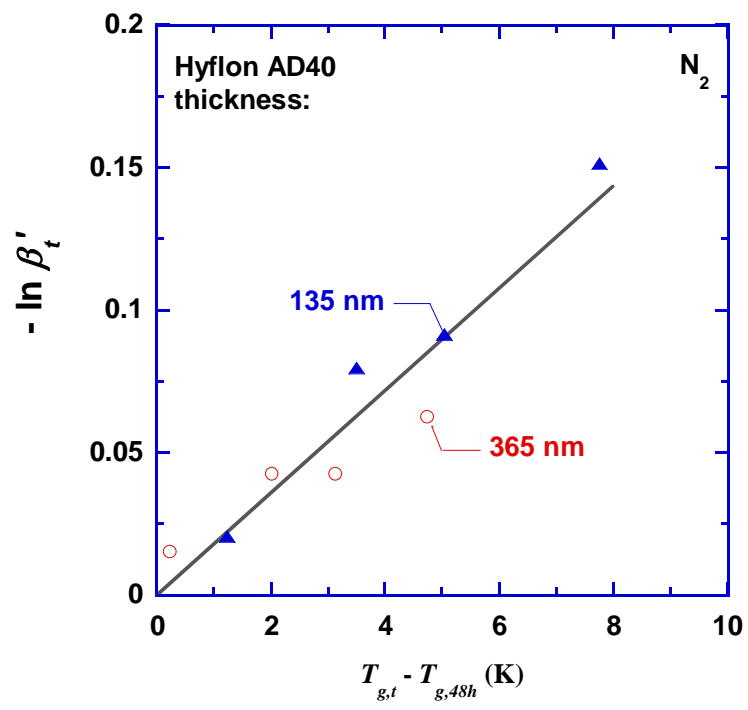

Fig. 6. Correlation of the permeance reduction (as represented by $\beta_{t}{ }^{\prime}$ ) with the increase in $T_{g}$ for the TFC membranes comprising selective layers at various thicknesses. The lines are the best fits based on Eq. 8 .

The slope of the fitting lines in Fig. 6 is $\alpha_{g} B_{A} / f_{48 h}^{2}$, which can be used to derive $B_{A}$ values assuming that $B_{A}$ and $\alpha_{g}$ are independent of the film thickness. The $f$ value changes only slightly with varying film thicknesses, based on Eqs. 3 and 6. For example, as the film thickness decreases from $370 \mathrm{~nm}$ to $50 \mathrm{~nm}$, the $f$ value changes from 0.2574 to 0.2579 for Teflon AF1600 
at $48 \mathrm{~h}$ aging. Therefore, the $f$ value is assumed to equal to that of the bulk polymer (cf. Table 1) to simply the analysis. The $B_{A}$ values for various gases are calculated and the results are recorded in Table 3. The uncertainty for the $B_{A}$ values are estimated based on error propagation for each parameter [43].

\section{Table 3}

$B_{A}$ values for the three perfluoropolymers in TFC membranes based on the best fits from Fig. 6 .

\begin{tabular}{lcccc}
\hline Polymers & $\mathrm{N}_{2}$ & $\mathrm{CH}_{4}$ & $\mathrm{CO}_{2}$ & $\mathrm{H}_{2}$ \\
\hline Teflon AF1600 & $11 \pm 3.4$ & $11 \pm 3.4$ & $7.9 \pm 2.6$ & $7.7 \pm 2.7$ \\
Hyflon AD80 & $3.0 \pm 1.1$ & $2.3 \pm 0.8$ & $2.6 \pm 0.9$ & $2.3 \pm 0.8$ \\
Hyflon AD40 & $3.0 \pm 1.2$ & $2.1 \pm 0.8$ & $2.0 \pm 0.9$ & $1.7 \pm 0.7$ \\
\hline
\end{tabular}

The $B_{A}$ values depend on gas molecule size and polymer type, and they are often used as adjustable parameters to fit the data in a series of polymers, instead of predicting gas permeability [18-21]. To evaluate these constants in the perfluoropolymers, Fig. 7 shows the effect of free volume on gas permeability in perfluoropolymers, including Teflon AF2400 $(f=0.33)$, Teflon AF1600 $(f=0.29)$, Hyflon AD80 $(f=0.23)$, Hyflon AD60 $(f=0.23)$ and Cytop $(f=0.21)$ [44]. Using Eq. 2, the $B_{A}$ values are 2.2, 2.6, 2.0 and 1.6, for $\mathrm{N}_{2}, \mathrm{CH}_{4}, \mathrm{CO}_{2}$ and $\mathrm{H}_{2}$, respectively. Except for Teflon AF1600, the $B_{A}$ values from thin film aging data based on Eq. 8 are consistent with those from the bulk polymers based on Eq. 2. Such consistency is impressive, considering that the thin film aging data are involved with gas permeances and $T_{g}$ as a function of aging time. 


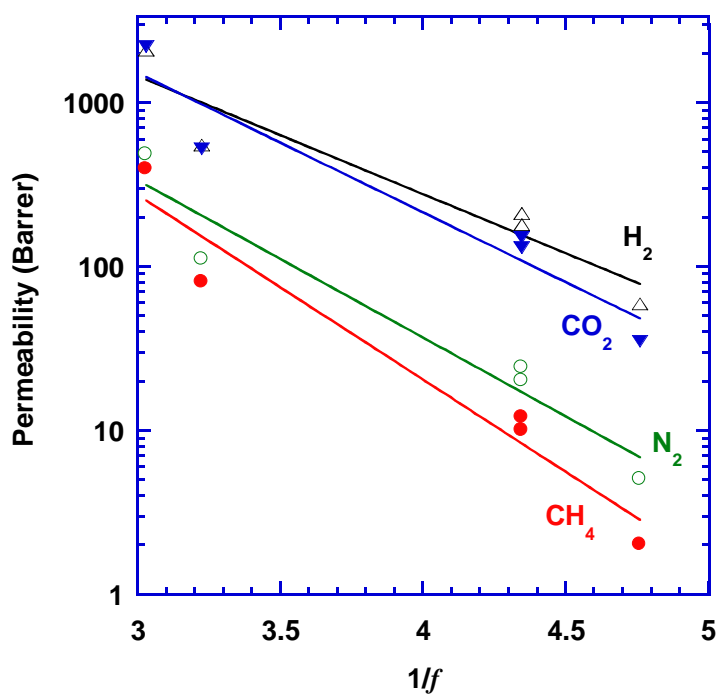

Fig. 7. Gas permeability as a function of $1 / f$ for perfluoropolymers including Teflon AF2400, Teflon AF1600, Hyflon AD80, Hyflon AD60 and Cytop [44].

\subsection{Physical aging rate of perfluoropolymers in TFC membranes}

Polymer physical aging can be characterized by physical aging rate, $r$, which is defined in Eq. $9[4,45,46]$ :

$r=-\frac{1}{V}\left[\frac{\partial V}{\partial \ln t}\right]_{P T}=\left[\frac{\partial \ln \rho}{\partial \ln t}\right]_{P T}=\left[\frac{\partial \ln (1-f)}{\partial \ln t}\right]_{P T}$

The $r$ values are typically obtained by monitoring polymer volume or density as a function of aging time [13]. For example, ellipsometer has been used to monitor refractive index of thin film polymers, which can be used to derive polymer density and thus physical aging rate $[7,47]$. However, these approaches cannot be applied to the thin selective layers in TFC membranes, due to the microporous supports beneath the selective layer. Alternatively, the $f$ values can be estimated using the apparent $T_{g}$ values and Eqs. 3 and 6, and thus the $r$ values for the thin film in TFC membranes can be estimated. 
Fig. 8 compares physical aging rate of selective layers in TFC membranes with that of freestanding films including perfluoropolymers and hydrocarbon polymers as a function of their corresponding $f$ values. All films have a thickness of about $400 \mathrm{~nm}$, except poly(1-trimethyl-1silyl propyne) (PTMSP) with a thickness of $700 \mathrm{~nm}$. The $r$ values for freestanding films were estimated based on the density change derived from the ellipsometer data $[45,46]$. For freestanding hydrocarbon polymers, decreasing free volume decreases the aging rate. For example, PTMSP $(f=0.290)$ shows a $r$ value of $6.2 \times 10^{-3}$, while PSf $(f=0.145)$ exhibits a $r$ value of $7.4 \times 10^{-4}$. On the other hand, perfluoropolymers demonstrate different trend from hydrocarbon polymers. The $r$ values for perfluoropolymer films in TFC membranes or freestanding form are both independent of free volume. The $r$ values are also much lower for perfluoropolymers than for hydrocarbon polymers, though they may have comparable $f$ values.

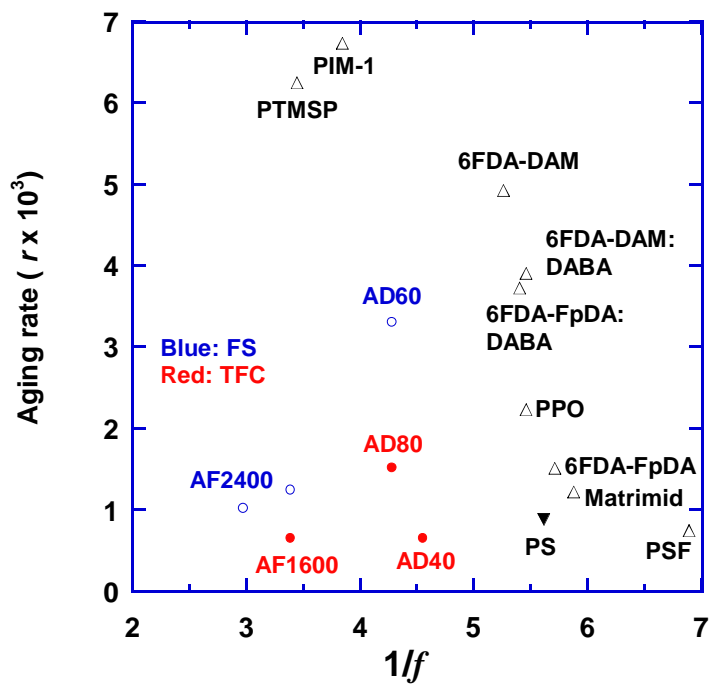

Fig. 8. Comparison of $r$ as a function of $1 / f$ for perfluoropolymer thin films in TFC membranes (TFC, •) (this study) with perfluoropolymer freestanding films (FS, ०) [46], and freestanding thin films of hydrocarbon polymers $(\Delta)$ and polystyrene $(\boldsymbol{\nabla})$ [46]. All of the films have a thickness of $\sim 400 \mathrm{~nm}$, except that PTMSP has a thickness of $700 \mathrm{~nm}$. 
Physical aging rate can be directly related to the permeance reduction rate using the following equation, which is derived by combining Eqs. 2 and 9 [6]:

$\frac{d \ln P_{A}}{d \ln t}=-B_{A} r \frac{1-f}{f^{2}}$

Fig. 9a presents the dependence of $d \ln P_{A} / d \ln t$ as a function of $r(1-f) / f^{2}$ for $\mathrm{N}_{2}$. The $B_{A}$ value can be assumed to be independent of polymer types [18], and the data can be modeled using a linear line. As shown in Fig. 9a, Eq. 10 can reasonably describe the data, validating the model. The model has also been confirmed for polysulfone (PSf) and Matrimid, where the $f$ values were obtained based on the density extracted from ellipsometer results [6].

(a)

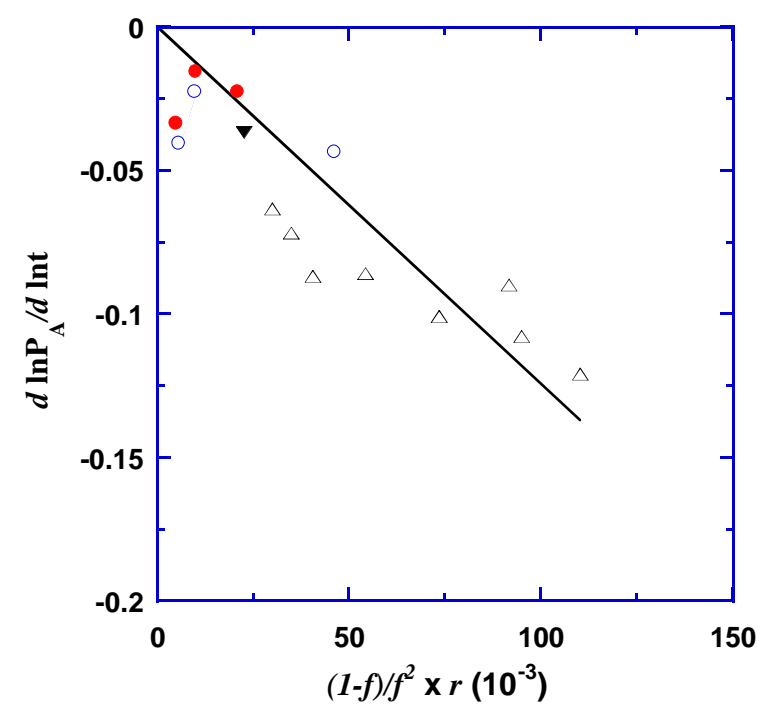

(b)

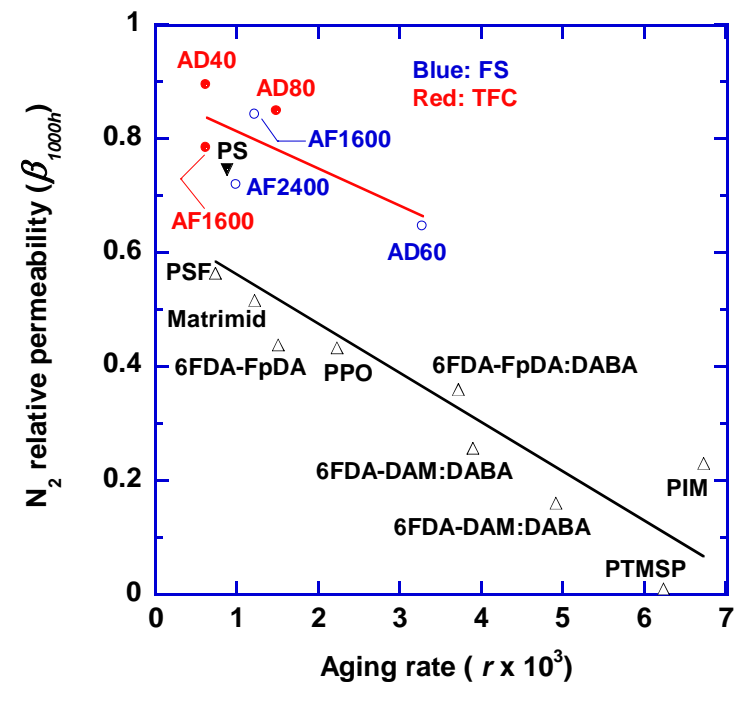

Fig. 9. (a) Validation of Eq. 10 by correlating $d \ln P_{A} / d \ln t$ and $r(1-f) / f^{2}$, and (b) effect of aging rate on $\mathrm{N}_{2}$ relative permeability for perfluoropolymer thin films in TFC membranes (TFC, •), perfluoropolymer freestanding films (FS, ०) [46], and freestanding thin films of hydrocarbon polymers $(\Delta)$ and polystyrene $(\boldsymbol{\nabla})$ [46]. All of the films have a thickness of $\sim 400 \mathrm{~nm}$, except that PTMSP has a thickness of $700 \mathrm{~nm}$.

Fig. $9 \mathrm{~b}$ compares the $\mathrm{N}_{2}$ relative permeability $\left(\beta_{1000 h}\right)$ in these polymers. $\beta_{1000 h}$ is defined as the ratio of gas permeability at an aging time of $1000 \mathrm{~h}$ to that at $1 \mathrm{~h}$, which has been reported in 
Part I of this study [7]. With similar $r$ values, perfluoropolymers have much higher free volume than hydrocarbon polymers, and thus higher $\beta_{1000 h}$ values, as confirmed by Eq. 10. In addition, for polymers with similar $f$ values, greater aging rate leads to more rapid permeation reduction rate, as exemplified by PTMSP $\left(f=0.29 ; r=6.2 \times 10^{-3}\right.$; and $\left.\beta_{1000 h}=0.01\right)$ and Teflon $\operatorname{AF1600~}(f=$ $0.29 ; r=6.3 \times 10^{-4}$, and $\left.\beta_{1000 h}=0.78\right)$.

The permeance reduction rate is exponentially proportional to the polymer physical aging rate (cf. Eq. 10). Therefore, designing advanced membrane polymers with good stability against physical aging requires an understanding of the relationship between polymer structure and physical aging rate. The backbones of glassy polymers are often considered immobile below $T_{g}$, and physical aging is suggested to be caused by side chain mobility $[6,12,47,48]$, resulting in the decrease in polymer free volume. Side chain mobility can be related to secondary relaxation of glassy polymers at temperatures below $T_{g}$ [49-54]. In the Supplemental Information, we summarize the physical aging rate of several polymers with their characteristic temperatures corresponding to the first, second, and third relaxation mode, as well as the activation energy. However, no clear trend is observed. The understanding of the polymer structure and physical aging rate relationship requires systematic study of secondary relaxation of polymers relevant to membrane applications, which is lacking in the literature and beyond the scope of this study.

\section{Conclusion}

Thin film glassy polymers are subjective to physical aging, which decreases gas permeability over time. There is a critical need to understand the structure and property relationship to design advanced membrane materials with good stability over time, together with high permeability and selectivity. The Part I of this study reports gas permeance in two-layer TFC membranes with 
perfluoropolymers as the selective layers. In this Part II study, a new nano-thermal analysis was used to determine the apparent $T_{g}$ of the thin selective layers in TFC membranes in situ. The apparent $T_{g}$ increases with physical aging, and thinner films initially shows lower $T_{g}$ than the thicker ones. However, at longer aging time, thinner films may exhibit higher $T_{g}$ than the thicker ones, due to the greater aging rate.

$T_{g}$ values are used to derive polymer factional free volume. The relationship between the permeance reduction and $T_{g}$ increase during the physical aging of thin films is successfully modeled using a simplified free volume model. The $B_{A}$ values obtained from the modeling are consistent with the literature data, validating the model and the interpretation of physical aging.

$T_{g}$ values are used to derive the physical aging rate of thin selective layers in TFC membranes. The rate of gas permeability reduction increases with increasing physical aging rate and decreasing $f$. Perfluoropolymers exhibit more stable gas permeability than hydrocarbon polymers because of higher free volume, and/or lower physical aging rate.

\section{Acknowledgments}

MY and HL gratefully acknowledge the financial support of this work by Korean Carbon Capture and Sequestration R\&D Center (KCRC), and the partial support from the U.S. National Science Foundation (NSF) under the CAREER award number 1554236. YD and SM acknowledge the financial support from NSF under the award number CBET-1264276 and IIP-1432952. 


\section{References}

[1] D. E. Sanders, Z. P. Smith, R. Guo, L. M. Robeson, J. E. McGrath, D. R. Paul, and B. D. Freeman, Energy-efficient polymeric gas separation membranes for a sustainable future: A review, Polymer, 54 (2013) 4729-4761.

[2] R. W. Baker and B. Low, Gas separation membrane materials: a perspective, Macromolecules, 47 (2014) 6999-7013.

[3] P. H. Pfromm and W. J. Koros, Accelerated physical aging of thin glassy polymer-films evidence from gas-transport measurements, Polymer, 36 (1995) 2379-2387.

[4] Y. Huang and D. R. Paul, Physical aging of thin glassy polymer films monitored by gas permeability, Polymer, 45 (2004) 8377-8393.

[5] B. W. Rowe, B. D. Freeman, and D. R. Paul, Physical aging of ultrathin glassy polymer films tracked by gas permeability, Polymer, 50 (2009) 5565-5575.

[6] Y. Huang, X. Wang, and D. R. Paul, Physical aging of thin glassy polymer films: Free volume interpretation, J. Membr. Sci., 277 (2006) 219-229.

[7] M. Yavari, T. Le, and H. Lin, Physical aging of glassy perfluoropolymers in thin film composite membranes. Part I. Gas transport properties, in press (2016).

[8] L. Zhu, M. Yavari, W. Jia, E. P. Furlani, and H. Lin, Effect of porous supports on the permeance of thin film composite membranes: Part II. Industrial polyethersulfone supports, Submitted.

[9] C. H. Lau, K. Konstas, A. W. Thornton, A. C. Liu, S. Mudie, D. F. Kennedy, S. C. Howard, A. J. Hill, and M. R. Hill, Gas-separation membranes loaded with porous aromatic frameworks that improve with age, Angew. Chem. Int. Ed., 54 (2015) 26692673.

[10] C. H. Lau, P. T. Nguyen, M. R. Hill, A. W. Thornton, K. Konstas, C. M. Doherty, R. J. Mulder, L. Bourgeois, A. C. Y. Liu, D. J. Sprouster, J. P. Sullivan, T. J. Bastow, A. J. Hill, D. L. Gin, and R. D. Noble, Ending aging in super glassy polymer membranes, Angew. Chem. Int. Ed., 53 (2014) 5322-5326.

[11] S. D. Kelman, B. W. Rowe, C. W. Bielawski, S. J. Pas, A. J. Hill, D. R. Paul, and B. D. Freeman, Crosslinking poly 1-(trimethylsilyl)-1-propyne and its effect on physical stability, J. Membr. Sci., 320 (2008) 123-134.

[12] J. M. Hutchinson, Physical aging of polymers, Prog. Polym. Sci., 20 (1995) 703-760.

[13] L. C. E. Struik, Physical aging in plastics and other glassy materials, Polym. Eng. Sci., 17 (1977) 165-173.

[14] D. Cangialosi, Dynamics and thermodynamics of polymer glasses, J. Phys-Condens. Mat., 26 (2014) 153101.

[15] Y. Huang and D. R. Paul, Experimental methods for tracking physical aging of thin glassy polymer films by gas permeation, J. Membr. Sci., 244 (2004) 167-178.

[16] D. W. Van Krevelen, Properties of polymers: Their correlation with chemical structure: Their numerical estimation and prediction from additive group contributions, Elsevier, Amsterdam, 1990.

[17] M. H. Cohen and D. Turnbull, Molecular transport in liquids and glasses, J. Chem. Phys., 31 (1959) 1164-1169.

[18] J. Y. Park and D. R. Paul, Correlation and prediction of gas permeability in glassy polymer membrane materials via a modified free volume based group contribution method, J. Membr. Sci., 125 (1997) 23-39. 
[19] H. Lin and B. D. Freeman, Materials selection guidelines for membranes that remove $\mathrm{CO}_{2}$ from gas mixtures, J. Mol. Struct., 739 (2005) 57-74.

[20] H. Lin, B. D. Freeman, S. Kalakkunnath, and D. S. Kalika, Effect of copolymer composition, temperature and carbon dioxide fugacity on pure- and mixed-gas permeability in poly(ethylene glycol)-based materials: free volume interpretation, J. Membr. Sci., 291 (2007) 131-139.

[21] H. Lin and M. Yavari, Upper bound of polymeric membranes for mixed-gas $\mathrm{CO}_{2} / \mathrm{CH}_{4}$ separations, J. Membr. Sci., 475 (2015) 101-109.

[22] D. W. Van Krevelen and K. Te Nijenhuis, Chapter 4 - Volumetric Properties, in D. W. V. K. by and K. T. Nijenhuis (Eds.), Properties of Polymers (Fourth Edition), Elsevier, Amsterdam, 2009, pp. 71-108.

[23] G. M. Odegard and A. Bandyopadhyay, Physical Aging of Epoxy Polymers and Their Composites, J. Polym. Sci. B Polym. Phys., 49 (2011) 1695-1716.

[24] M. Y. Efremov, J. T. Warren, E. A. Olson, M. Zhang, A. T. Kwan, and L. H. Allen, Thinfilm differential scanning calorimetry: A new probe for assignment of the glass transition of ultrathin polymer films, Macromolecules, 35 (2002) 1481-1483.

[25] J. L. Keddie, R. A. L. Jones, and R. A. Cory, Size-dependent depression of the glasstransition temperature in polymer-films, Europhys. Lett., 27 (1994) 59-64.

[26] J. E. Pye and C. B. Roth, Above, below, and in-between the two glass transitions of ultrathin free-standing polystyrene films: Thermal expansion coefficient and physical aging, J. Polym. Sci. B Polym. Phys., 53 (2015) 64-75.

[27] J. E. Pye, K. A. Rohald, E. A. Baker, and C. B. Roth, Physical aging in ultrathin polystyrene films: Evidence of a gradient in dynamics at the free surface and its connection to the glass transition temperature reductions, Macromolecules, 43 (2010) 8296-8303.

[28] J. A. Forrest, K. DalnokiVeress, J. R. Stevens, and J. R. Dutcher, Effect of free surfaces on the glass transition temperature of thin polymer films, Phys. Rev. Lett., 77 (1996) 2002-2005.

[29] J. A. Forrest and K. Dalnoki-Veress, The glass transition in thin polymer films, Adv. Colloid Interface Sci., 94 (2001) 167-196.

[30] P. Z. Hanakata, J. F. Douglas, and F. W. Starr, Interfacial mobility scale determines the scale of collective motion and relaxation rate in polymer films, Nat. Commun., 5 (2014) 4163.

[31] S. H. Maruf, D. U. Ahn, A. R. Greenberg, and Y. Ding, Glass transition behaviors of interfacially polymerized polyamide barrier layers on thin film composite membranes via nano-thermal analysis, Polymer, 52 (2011) 2643-2649.

[32] S. H. Maruf, D. U. Ahn, J. Pellegrino, J. P. Killgore, A. R. Greenberg, and Y. F. Ding, Correlation between barrier layer T-g and a thin-film composite polyamide membrane's performance: Effect of chlorine treatment, J. Membr. Sci., 405 (2012) 167-175.

[33] H. Lin and B. D. Freeman, Permeation and diffusion, in H. Czichos, L. E. Smith and T. Saito (Eds.), Springer-Handbook of Materials Measurement Methods, Springer, 2006, pp. 371-387.

[34] Chemours ${ }^{\mathrm{TM}}$ Teflon ${ }^{\circledR}$ AF amorphous fluoroplastic, https://chemours.com/Teflon_Industrial/en_US/products/product_by_name/teflon_af/ind ex.html, (accessed August 17, 2016). 
[35] S. Gao, Y. P. Koh, and S. L. Simon, Calorimetric glass transition of single polystyrene ultrathin films, Macromolecules, 46 (2013) 562-570.

[36] J. Mattsson, J. A. Forrest, and L. Börjesson, Quantifying glass transition behavior in ultrathin free-standing polymer films, Phys. Rev. E, 62 (2000) 5187-5200.

[37] C. M. Evans, H. Deng, W. F. Jager, and J. M. Torkelson, Fragility is a key parameter in determining the magnitude of $\mathrm{T}_{\mathrm{g}}$-confinement effects in polymer films, Macromolecules, 46 (2013) 6091-6103.

[38] K. Fukao, T. Terasawa, K. Nakamura, and D. Tahara, Heterogeneous and aging dynamics in single and stacked thin polymer films, in T. Kanaya (Ed.), Glass Transition, Dynamics and Heterogeneity of Polymer Thin Films, Advances in Polymer Science, Vol. 252, 2013, pp. 65-106.

[39] K. Dalnoki-Veress, J. A. Forrest, C. Murray, C. Gigault, and J. R. Dutcher, Molecular weight dependence of reductions in the glass transition temperature of thin, freely standing polymer films, Phys. Rev. E, 63 (2001) 031801.

[40] T. M. Murphy, B. D. Freeman, and D. R. Paul, Physical aging of polystyrene films tracked by gas permeability, Polymer, 54 (2013) 873-880.

[41] K. D. Dorkenoo and P. H. Pfromm, Accelerated physical aging of thin poly[1(trimethylsilyl)-1-propyne] films, Macromolecules, 33 (2000) 3747-3751.

[42] Y. Huang and D. R. Paul, Effect of film thickness on the gas-permeation characteristics of glassy polymer membranes, Ind. Eng. Chem. Res., 46 (2007) 2342-2347.

[43] P. R. Bevington, Data reduction and error analysis for the physical sciences, 2nd ed., New York, McGraw-Hill, 1992.

[44] T. C. Merkel, I. Pinnau, R. Prabhakar, and B. D. Freeman, Gas and vapor transport properties of perfluoropolymers, Materials Science of Membranes for Gas and Vapor Separation, John Wiley \& Sons, Ltd, 2006, pp. 251-270.

[45] R. R. Tiwari, Z. P. Smith, H. Lin, B. D. Freeman, and D. R. Paul, Gas permeation in thin films of "high free-volume" glassy perfluoropolymers: Part II. $\mathrm{CO}_{2}$ plasticization and sorption, Polymer, 61 (2015) 1-14.

[46] R. R. Tiwari, Z. P. Smith, H. Lin, B. D. Freeman, and D. R. Paul, Gas permeation in thin films of "high free-volume" glassy perfluoropolymers: Part I. Physical aging, Polymer, 55 (2014) 5788-5800.

[47] R. D. Priestley, C. J. Ellison, L. J. Broadbelt, and J. M. Torkelson, Structural relaxation of polymer glasses at surfaces, interfaces, and in between, Science, 309 (2005) 456-459.

[48] M. R. Pixton and D. R. Paul, Relationships between structure and transport properties for polymers with aromatic backbones, in D. R. Paul and Y. P. Yampol'skii (Eds.), Polymeric Gas Separation Membranes, CRC Press, Inc., Boca Raton, FL, 1994, pp. 83154.

[49] F. E. Karasz, W. J. Macknight, and J. Stoeltin, Dielectric properties of poly(2,6-dimethyl phenylene oxide), J. Appl. Phys., 41 (1970) 4357-4361.

[50] O. Yano and Y. Wada, Dynamic mechanical and dielectric relaxations of polystyrene below glass temperature, J. Polym. Sci. B Polym. Phys., 9 (1971) 669-686.

[51] S. J. Rigby and Dewhughe.D, Low-temperature dielectric-relaxation in polymers containing an aromatic group in main chain, Polymer, 15 (1974) 639-644.

[52] H. W. Starkweather, P. Avakian, R. R. Matheson, J. J. Fontanella, and M. C. Wintersgill, Low-temperature dielectric behavior of polymers and copolymers of tetrafluoroethylene, Macromolecules, 24 (1991) 3853-3856. 
[53] S. Kalakkunnath, D. S. Kalika, H. Lin, R. D. Raharjo, and B. D. Freeman, Molecular dynamics of poly(ethylene glycol) and poly(propylene glycol) copolymer networks by broadband dielectric spectroscopy, Macromolecules, 40 (2007) 2773-2781.

[54] S. Kalakkunnath, D. S. Kalika, H. Lin, R. D. Raharjo, and B. D. Freeman, Molecular relaxation in cross-linked poly(ethylene glycol) and poly(propylene glycol) diacrylate networks by dielectric spectroscopy, Polymer, 48 (2007) 579-589. 